\title{
Triptolide-induced suppression of phospholipase D expression inhibits proliferation of MDA-MB-231 breast cancer cells
}

\author{
Dong Woo Kang*, Ji Young Lee*, Deuk-hee Oh*, \\ Seon Yang Park, Tae Min Woo, Mi Kyoung Kim, \\ Mi Hee Park, Young Hoon Jang and Do Sik Min ${ }^{1}$ \\ Department of Molecular Biology \\ College of Natural Science \\ Pusan National University \\ Busan 609-735, Korea \\ ${ }^{1}$ Corresponding author: Tel, 82-51-510-3682; \\ Fax, 82-51-513-9258; E-mail, minds@ @usan.ac.kr \\ *These authors contributed equally to this work. \\ DOI 10.3858/emm.2009.41.9.074 \\ Accepted 18 May 2009
}

Abbreviation: TWHF, Tripterygium wilfordii Hook F

\begin{abstract}
In spite of the importance of phospholipase D (PLD) in cell proliferation and tumorigenesis, little is known about the molecules regulating PLD expression. Thus, identification of small molecules inhibiting PLD expression would be an important advance for PLDmediated physiology. We examined one such here, denoted "Triptolide", which was identified in a chemical screen for inhibitors of PLD expression using cell assay system based on measurement of PLD promoter activity. Triptolide significantly suppressed the expression of both PLD1 and PLD2 with sub- $\mu$ M potency in MDA-MB-231 breast cancer cells as analyzed by promoter assay and RT-PCR. Moreover, triptolide abolished the protein level of PLD in a time and dose-dependent manner. Triptolide-induced PLD1 downregulation was also observed in all the cancer cells examined, suggesting a general phenomenon detected in various cancer cells. Decrease of PLD expression by triptolide suppressed both basal and PMA-induced PLD activity. In addition, triptolide inhibited activation of $\mathrm{NF}_{\mathrm{KB}}$ which increased PLD1 expression. Ultimately, downregulation of PLD by triptolide inhibited proliferation of breast cancer cells. Taken together, we demonstrate that triptolide suppresses the expression of PLD via inhibition of NFKB activation and then de-
\end{abstract}

creases cell proliferation.

Keywords: breast neoplasms; cell proliferation; gene expression regulation, neoplastic; NF- $\mathrm{B}$; phospholipase D; triptolide

\section{Introduction}

Triptolide is a natural, biologically active compound as a diterpenoid triepoxide originally purified from the Chinese herb Tripterygium wilfordii Hook $F$ (TWHF). This natural product used in traditional Chinese medicine for centuries, has a myriad of therapeutic uses against inflammation and autoimmune disease (Chen, 2001; Qiu et al., 2003, Xiang and Zhang, 2005). Antiproliferative activity of triptolide has been shown with many different types of cancer cells in vitro and in vivo (Shamon et al., 1997; Tengchaisri et al., 1998; Chang et al., 2001; Kiviharju et al., 2002, Fidler et al., 2003; Yang et al., 2003). Therefore, triptolide might be clinically effective for tumor chemotherapy. Anti-inflammatory and anti-proliferative properties of triptolide have been associated with inhibition of NFKB (Lee et al., 1999; Qiu et al., 1999; Liu et al., 2000). Although these studies shed some lights on triptolide actions, there are still many gaps left and hard to explain why triptolide has such a broad biological function. The exact targets and molecular mechanism of action of triptolide are still unknown.

PLD catalyzes the hydrolysis of phosphatidylcholine to generate phosphatidic acid and choline. Two human PLD isozymes, phosphatidylcholine-specific PLD1 and PLD2, have been described (Hammond et al., 1995; Colley et al., 1997). The catalytic and regulatory features of PLD1 are remarkably different from those of PLD2 although both isozymes have about $50 \%$ of amino acid sequence homology and similar structural domain (Frohman et al., 1999; Exton 2002). Abnormalities in PLD expression and activity have been observed in many human cancers (Foster and $\mathrm{Xu}$, 2003). We previously reported that overexpression of PLD isozymes causes anchorage-independent growth and induces tumorigenesis (Min et al., 2001). We and other research group have reported 
that PLD activity has been implicated in cell motility and tumor invasion and correlated with increased protease secretion (Williger et al., 1999; Park et al., 2009). These findings suggest that PLD is a critical molecule in tumorigenesis. Despite gathering evidence regarding the regulation of PLD activity in cell function, little is known about the functional role and regulatory mechanisms of PLD expression.

Recently, we have reported that PMA as a tumor promoter enhances PLD1 expression via NFКBdependent signaling pathway and increases cell proliferation and invasion (Kang et al., 2008). Thus, we set out to identify compounds inhibiting PLD expression using stable cells expressing PLD promoter. We found that triptolide inhibited the expression and activity of PLD in MDA-MB-231 human breast cancer cell which is highly invasive and has high level of PLD activity (Chen et al., 2003, 2005). In this study, we demonstrate that downregulation of PLD as a new downstream target of triptolide suppresses cell proliferation.

\section{Results}

\section{Triptolide inhibits PLD expression in MDA-MB-231 human breast cancer cells}

Since PLD has emerged as a critical regulator of cell proliferation and survival (Foster and $\mathrm{Xu}$, 2003), we tried to screen small molecules inhibiting the expression of PLD using cell assay system for measurement of PLD promoter activity. We found that triptolide significantly inhibited PLD promoter activity in stable cells expressing PLD promoter.

A
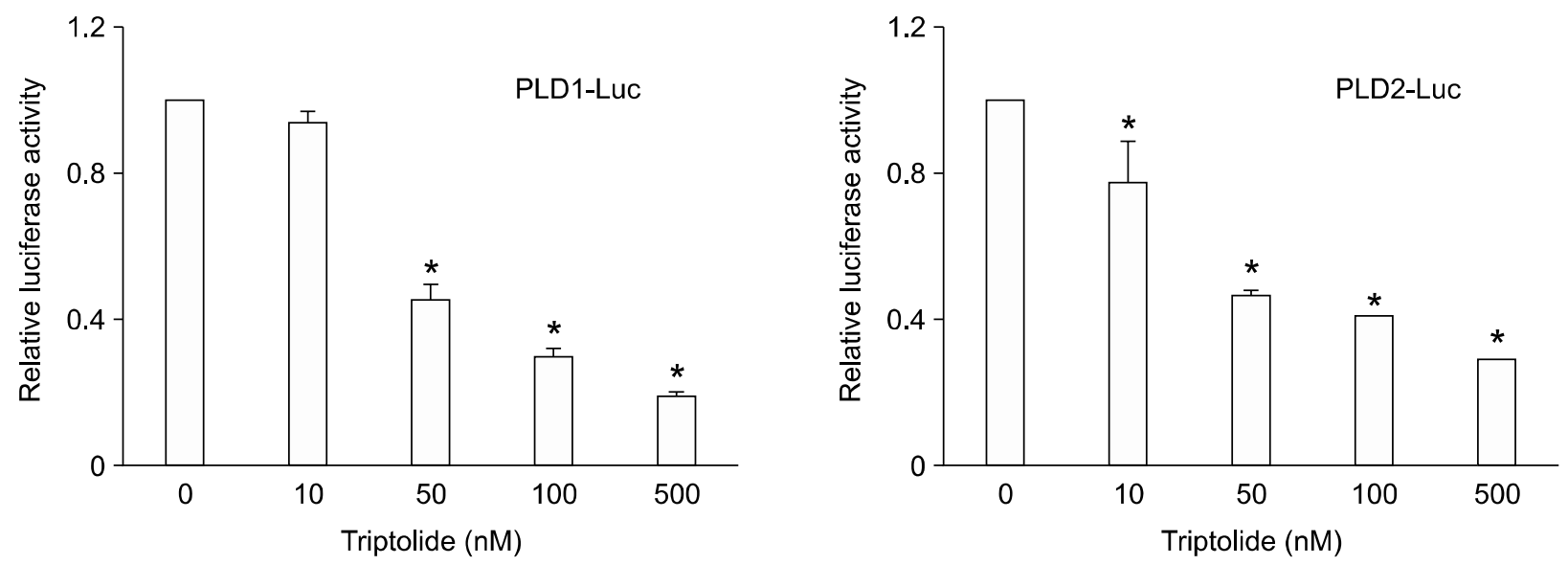

B
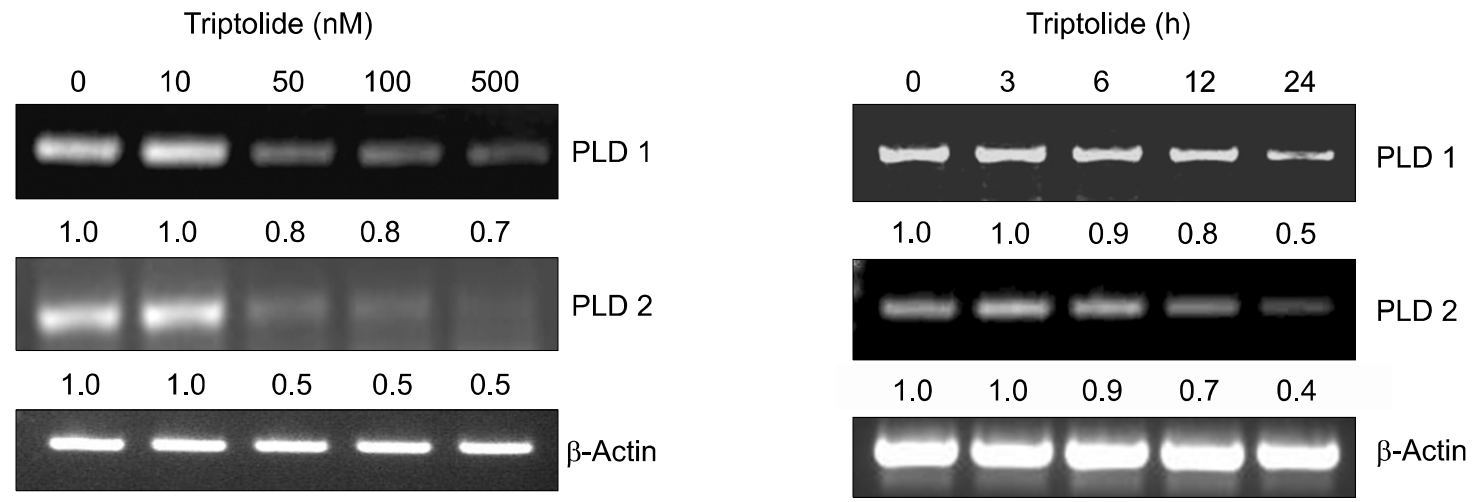

Figure 1. Triptolide downregulates transcriptional level of PLD isozymes in MDA-MB-231 breast cancer cells. (A) MDA-MB-231 cells were transiently transfected with PLD1 or PLD2 reporter constructs and treated with the indicated concentration of triptolide for $18 \mathrm{~h}$, and luciferase activity was subsequently measured. Each value represents the mean \pm S.D. of five independent experiments. ${ }^{*} P<0.05$ versus non-treatment (B) MDA-MB-231 cells were treated with the indicated concentration of triptolide for $24 \mathrm{~h}$ or $100 \mathrm{nM}$ of triptolide for the indicated times, and then PLD expression was analyzed by RT-PCR. The level of PLD1 expression was determined by densitometer analysis. The data are representative of results obtained from three experiments. 
A

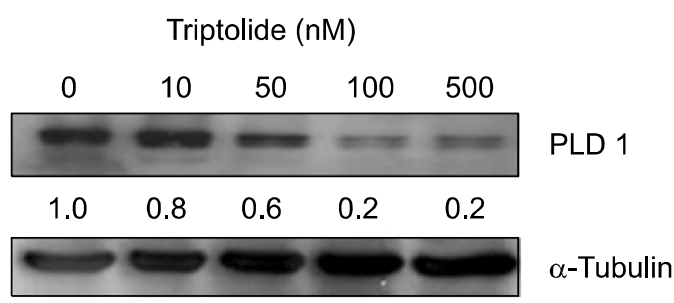

B

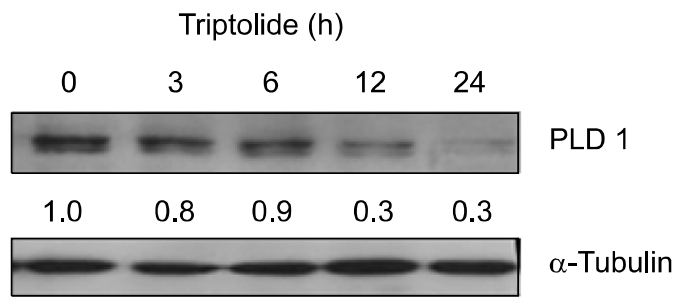

Figure 2. Triptolide suppresses expression of PLD protein in MDA-MB-231 cells. MDA-MB-231 cells were treated with the indicated concentration of triptolide for $24 \mathrm{~h}(\mathrm{~A})$ or $100 \mathrm{nM}$ of triptolide for the indicated time. The cell lysates were analyzed by Western blot using antibody to PLD. The level of PLD1 expression was determined by densitometer analysis. The data are representative of results obtained from three experiments.

We examined the effects of different concentrations of triptolide on PLD promoter activity in MDA-MB-231 breast cancer cells. MDA-MB-231 cells were transiently transfected with PLD1- or PLD2-luciferase reporter constructs and treated with various dose of triptolide. As shown in Figure $1 \mathrm{~A}$, triptolide suppressed both PLD1 and PLD2 promoter activity in a dose-dependent manner, with $50 \%$ decrease of expression observed at approxi- mately $50 \mathrm{nM}$. It decreased the promoter activity of both PLD isozymes with similar inhibitory potency in MDA-MB-231 cells. We further investigated whether triptolide-induced PLD1 suppression may be regulated in a transcriptional level. Treatment with triptolide for $24 \mathrm{~h}$ decreased the expression level of PLD1 and PLD2 mRNA in a dose dependent manner with approximately $50 \%$ inhibition at $50 \mathrm{nM}$ as analyzed by RT-PCR (Figure 1B). Triptolide also downregulated the expression level of both PLD1 and PLD2 in a time dependent manner (Figure 1B). In addition, the inhibition of PLD mRNA level by triptolide resulted in the corresponding suppression of PLD1 protein in a doe and timedependent manner as analyzed by immunoblot (Figure 2A and 2B). MDA-MB-231 breast cancer cells expressed predominantly PLD1 protein. Dose and time kinetics of triptolide-induced suppression of PLD1 protein show a similar pattern with those of transcriptional expression. Taken together, these results suggest that expression of PLD isozymes was down-regulated by triptolide at both transcriptional and post-transcriptional levels.

\section{Downregulation of PLD by triptolide in various human cancer cells}

To examine whether triptolide-induced expression of PLD1 is specific to the MDA-MB-231 cells or also occurs in other human cancer cells, various cancer cells including the glioblastoma (U373) and colon cancer cells (DKO, HCT-116, SW480, DLD-1) and breast cancer cells (HS578T, MCF-7) were treated with triptolide for $24 \mathrm{~h}$ and analyzed by Western blot (Figure 3). In most cells examined, PLD1 protein was predominantly detected but PLD2 was not detectable. Triptolide-induced suppression of PLD1 expression was noted in all of

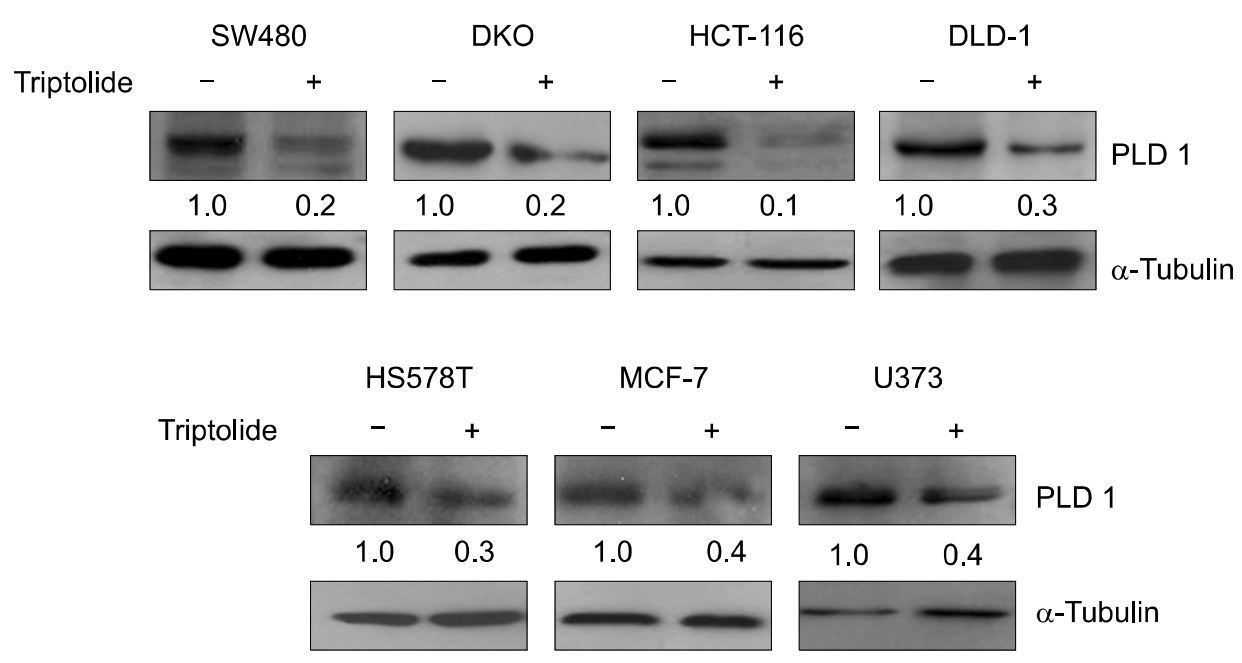

Figure 3. Triptolide-induced PLD suppression occurs in various human cancer cells. Various human cancer cells were treated with triptolide $(100 \mathrm{nM})$ for $24 \mathrm{~h}$. The cell lysates were analyzed by western blot using the antibody to PLD or a-tubulin. The level of PLD1 expression was determined by densitometer analysis. These blots are representative of results obtained from three experiments. 
A

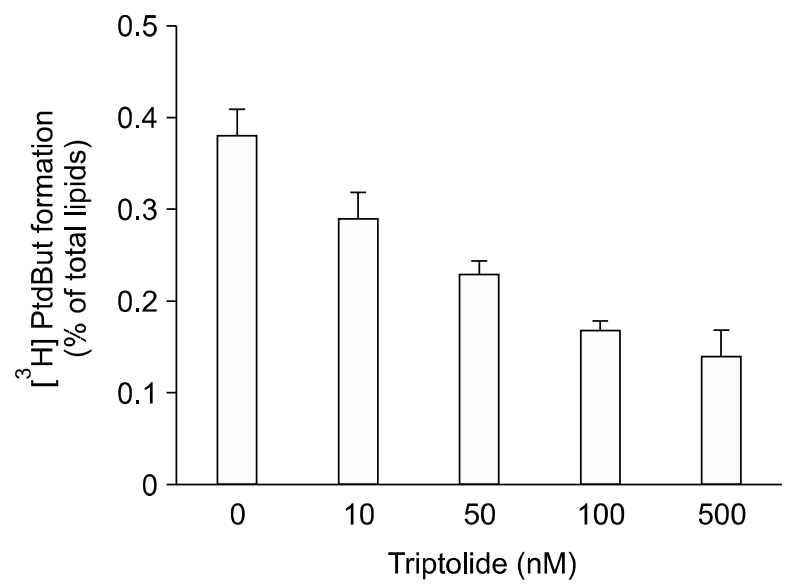

B

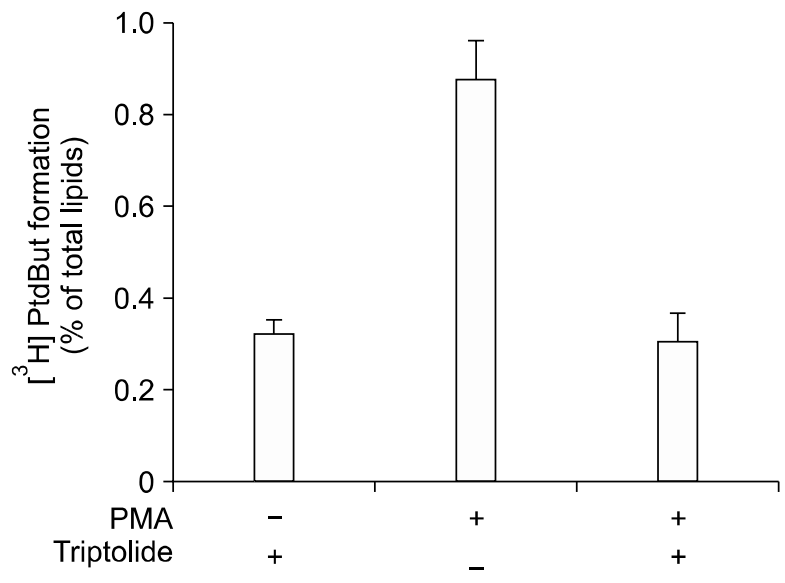

Figure 4. Triptolide inhibits both basal and PMA-induced PLD activation. MDA-MB-231 cells were labeled with $\left.{ }^{3} \mathrm{H}\right] \mathrm{myristate}$ for $12 \mathrm{~h}$, and were treated with the indicated concentration of triptolide for $30 \mathrm{~min}(\mathrm{~A})$ or pretreated with triptolide $(100 \mathrm{nM})$ for 30 min and treated with PMA (100 nM) for $1 \mathrm{~h}$ (B). Then, the PLD activity was measured as described under "Methods." Each value represents the mean \pm S.D. of five independent experiments.

the cancer cells examined. Therefore, it is suggested that downregulation of PLD by triptolide is a general phenomenon.

\section{Triptolide decreases both basal and PMA-induced PLD activation}

Next, we examined whether suppression of PLD1 expression by triptolide decrease its enzymatic activity. As shown in Figure 4A, treatment with triptolide inhibited basal PLD activity in a dose-dependent manner in MDA-MB-231 cells. Moreover, triptolide inhibited PLD activity stimulated by PMA which is known as a PLD activator (Figure 4B). These data demonstrate that triptolide-induced suppression of PLD expression leads to a decrease of both basal and PMA-induced PLD activity.

Triptolide suppresses PLD expression via inhibition of NFKB transcriptional activity

Next, we tried to investigate the molecular mechanism for triptolide-induced PLD suppression. Recently, we have reported that PMA induces selec-
A

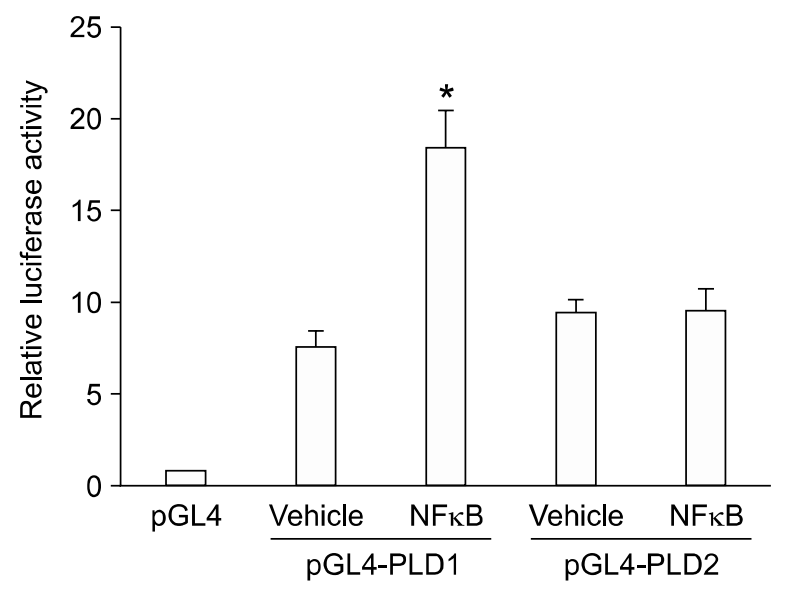

B

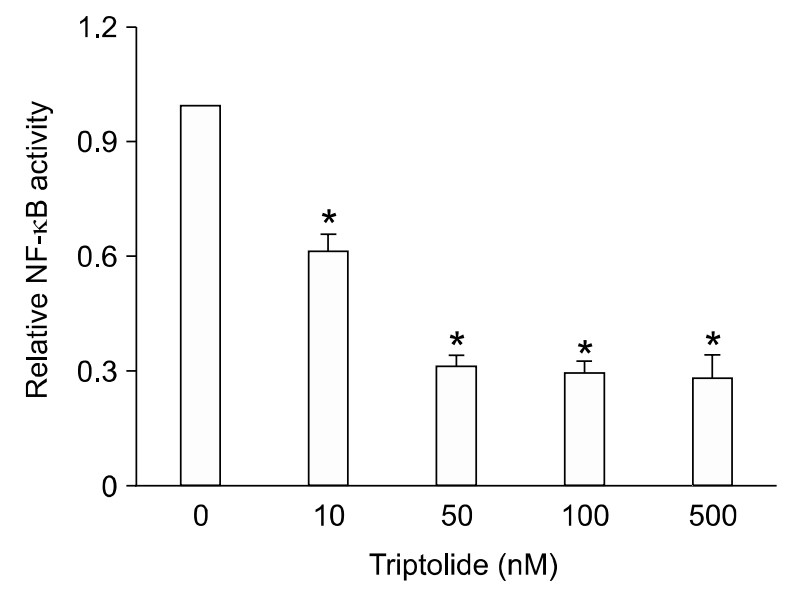

Figure 5. Triptolide suppresses PLD expression via inhibition of NFKB transcriptional activity. (A) MDA-MB-231 cells were cotransfected with $p G L 4-P L D$ and $N F \kappa B$ (p65) and then luciferase activity was subsequently measured. Each value represents the mean \pm S.D. of five independent experiments. ${ }^{*} P$

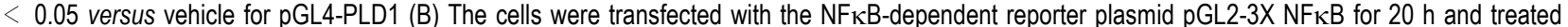
with the indicated concentration of triptolide and then their luciferase activity was measured. A Renilla luciferase control vector was co-transfected to normalize the transfection efficiency. Each value represents the mean \pm S.D. of five independent experiments. ${ }^{*} P<0.05$ versus non-treatment. 
tively PLD1 expression via NFאB (Kang et al., 2008). Ectopic expression of NFKB (p65) enhanced the promoter activity, protein expression, and enzymatic activity of PLD1, but did not significantly affect those of PLD2 in HCT116 colorectal cancer cells (Kang et al., 2008). Two NFKB binding sites present in the PLD1 promoter was responsible for PMA-induced PLD1 expression (Kang et al., 2008). We found that NFKB also enhanced PLD1 expression but not PLD2 in MDA-MB-231 cells (Figure $5 A$ ). Therefore, we examined whether triptolide affects transcriptional activity of NF $\kappa B$ in MDA-MB-231 cells. As shown in Figure 5B, triptolide significantly inhibited transactivation of $N F_{\kappa} B$ in a dose-dependent manner. These data suggest that triptolide might suppress PLD1 expression via inhibition of NF $\kappa$ B transactivation and abolish PLD2 expression via mechanism independent of $N F \kappa B$ transactivation.

\section{Triptolide-induced PLD suppression inhibits the proliferation of breast cancer cells}

Next, we investigated the biological significance of triptolide-induced PLD downregulation. The proliferation of MDA-MB-231 cells was examined by treatment with triptolide as measured by MTT assay. Triptolide inhibited cell viability in a dose-dependent manner (Figure 6A). Moreover, depletion of PLD1 using siRNA led to decreased proliferative activity (Figure 6B). These data suggest that inhibitory effect of triptolide on cell proliferation is mediated at least by triptolide-induced PLD repression.

\section{Discussion}

In the present study, we demonstrate that triptolide downregulates expression and activity of PLD and then inhibits proliferation of breast cancer cells. These effects appear to be mediated through suppressing the transactivation of $\mathrm{NF}_{\kappa} \mathrm{B}$. Multiple protein targets both upstream and downstream of PLD have been linked to propagation of survival signals and metastasis in cancer progression.

Overexpression and elevated activity of PLD result in cellular transformation and has been implicated in multiple human cancers including colorectal (Saito et al., 2007; Kang et al., 2008), breast (Noh et al., 2000), renal (Zhao et al., 2000), gastric carcinoma (Uchida et al., 1999), and thyroid cancers (Kim et al., 2008). Stable cells overexpressing PLD1 and PLD2 demonstrate anchorage-independent growth and tumorigenesis in nude mice (Min et al., 2001; Buchanan et al., 2005). Thus, it is suggested that PLD plays an important role in cancer progression and that PLD could be a target for therapy in cancer. It thus is conceivable that a strategy aiming to block the effect of PLD would decrease expression and activity of the PLD, breaking down a tumor-promoting loop and there reducing tumor growth.

We have identified triptolide via chemical screen for inhibitors of PLD expression using cell assay system based on measurement of PLD promoter activity. Triptolide has been investigated for many of its potential therapeutic uses, including reduction of solid tumor masses, and is in clinical trials based on its potent antitumor effects in a prostate cancer
A

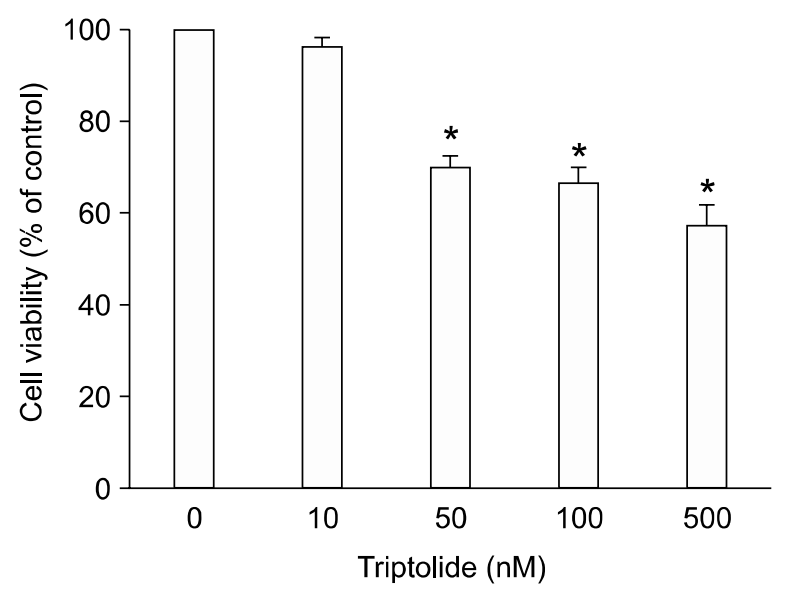

B

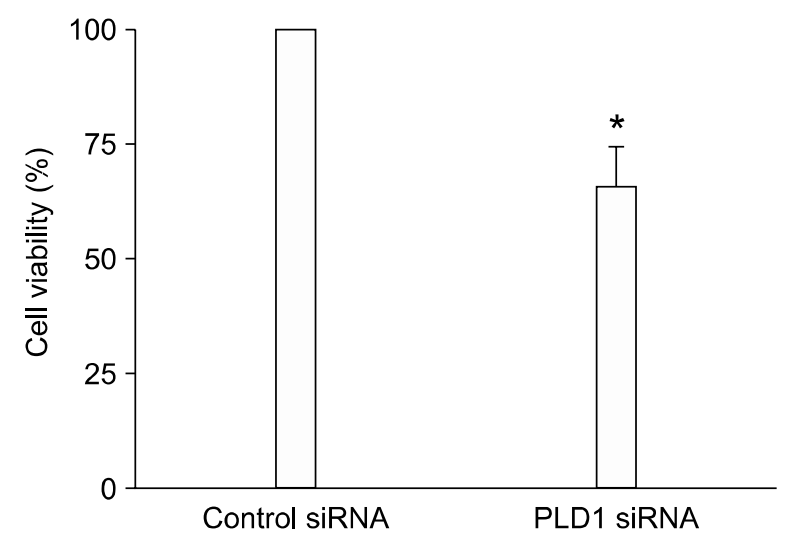

Figure 6. Triptolide-induced PLD downregulation inhibits proliferation of breast cancer cells. (A) MDA-MB-231 cells were treated with the indicated concentration of triptolide for $24 \mathrm{~h}$. The cell viability was measured using MTT assay. Each value represents the mean \pm S.D. of three independent experiments. ${ }^{*} P<0.05$ versus non-treatment (B) The cells were transfected with siRNA for control or PLD1 and the cell viability was measured using MTT assay. The data represents the mean \pm S.D. of five independent experiments. ${ }^{*} P<0.05$ versus control siRNA. 
model (Kiviharju et al., 2002). Because the natural source of triptolide, the medicinal vine, Tripterygium wilfordii Hook $\mathrm{F}$, has a long history in Chinese traditional medicine, it is hoped that triptolide will be promising therapeutic candidate for the treatment of cancer. Although several intracellular pathways such as $\mathrm{NF} \kappa \mathrm{B}, \mathrm{Bcl}-2, \mathrm{PI} 3 \mathrm{~K}$, and c-myc have been reported to be responsible for the mechanisms underlying the action of triptolide (Lee et al., 1999; Kiviharju et al., 2002; Miyata et al., 2005; Ko et al., 2007), our results show that downregulation of PLD by triptolide is a key mechanism for reduction of cell proliferation.

Triptolide abolished expression of both PLD1 and PLD2 at the transcriptional level. Moreover, triptolide inhibited both basal and PMA-induced PLD activity. Triptolide-induced PLD suppression inhibited proliferation of breast cancer cells. Recently, we have reported that tumor promoter signal such as PMA stimulates selectively PLD1 expression by increasing the binding of $N F \kappa B$ to PLD1 promoter (Kang et al., 2008). NFאB did not affect PLD2 expression (Kang et al., 2008).

The antitumor proliferation induced by triptolide has been reported to be associated with the downregulation of $\mathrm{NF} \kappa \mathrm{B}$ activity (YinJun et al., 2005). We found that triptolide inhibited transactivation of NF $\kappa B$ in MDA-MB0231 breast cancer cells. Thus, it is suggested that triptolide-mediated PLD1 repression might be due to inhibition of $N F \kappa B$ activity by triptolide. However, it is likely that triptolide inhibits PLD2 expression via distinct pathway from that of PLD1 since $N F \kappa B$ is not responsible for PLD2 expression. Until now, the lack of potent and isoform-selective inhibitors has limited progress in defining the cellular roles of PLD. Recently, isoform-selective PLD inhibitors have been developed (Scott et al., 2009) and may facilitate a better understanding of the biological roles played by the respective PLD isozymes. We have identified triptolide as dual inhibitor for PLD1 and PLD2 expression. In summary, we have identified PLD as a candidate target for the therapeutic action of the traditional Chinese medicine-derived natural product triptolide. Triptolide could be used as dual inhibitor for PLD1 and PLD2 expression. It is expected that drugs modulating function of PLD as a therapeutic target will develop as a promising strategy applied to a broad spectrum of cancer treatment.

\section{Methods}

\section{Cells and material}

Breast cancer cells (MDA-MB-231, MCF7, HS578T), col- orectal cancer cells (HCT116, DLD-1, DKO, SW480) and glioma cells (U373) were purchased from ATCC (Rockville, MA). MCF7, HS578T, DLD-1, and HCT116 cells were incubated with RPMI 1640 medium containing 10\% heatinactivated FBS with penicillin-streptomycin (Gibco BRL, Grand Island, NY). MDA-MB231, DKO, SW480 and U373 cells were grown in DMEM supplemented with $10 \%$ FBS. Triptolide and PMA was purchased from Sigma Chemical Company (St. Louis, MO). The promoter region of human PLD1 and PLD2 gene has been cloned (Kang et al., 2008).

\section{Transient transfection and luciferase assay}

Cells were grown to $50-60 \%$ confluence. Plasmid or siRNA was transiently transfected into MDA-MB231 cells using Lipofectamine Plus reagent (Invitrogen) according to the manufacturer's instruction. For luciferase reporter assay, the cells were seeded in 24-well plates and transiently transfected with $100 \mathrm{ng}$ of promoter constructs and $10 \mathrm{ng}$ of pRL-TK (internal control). The activities of firefly and renilla luciferase in the cellular extracts were measured using the Dual-Luciferase Assay kit (Promega) according to the manufacturer's instructions. For the NFKB transactivation assay, $p G L 2-3 X N F \kappa B$, which contained three tandem repeats of the $N F_{\kappa B}$ binding motif, was used.

\section{RNA isolation and RT-PCR}

Total RNA was isolated from cells using TRIzol reagent. First-strand cDNA was synthesized using $5 \mu \mathrm{g}$ total RNA with Moloney murine leukemia virus reverse transcriptase (MMLV-RTase) (Promega, Mannheim, Germany). The reaction was incubated at $80^{\circ} \mathrm{C}$ for $5 \mathrm{~min}, 42^{\circ} \mathrm{C}$ for $90 \mathrm{~min}$, and MMLV-RTasse was inactivated at $95^{\circ} \mathrm{C}$ for $5 \mathrm{~min}$. The synthesized cDNA was amplified using PLD1, PLD2 and $\beta$-actin primers with an eppendorf thermocycler (Eppendorf Scientific, Westbury, NY). PCR products were analyzed by agarose gel electrophoresis with ethidium bromide staining.

\section{Western blot analysis}

The cells were analyzed by immunoblotting as described previously (Kang et al., 2008). Enhanced chemiluminescence $(E C L)$ reagents were obtained from Amersham Biosciences (Piscataway, NJ). ECL was used to detect the signal. The following antibodies were used: anti- $\beta$-tubulin antibody was obtained from Santa Cruz Biotechnology (Santa Cruz, CA). Rabbit polyclonal anti-PLD antibody that recognizes both PLD1 and PLD2 was generated as described previously (Min et al., 2001).

\section{PLD activity assay}

PLD activity was assessed by measuring the formation of $\left[{ }^{3} \mathrm{H}\right]$ phosphatidylbutanol, the product of PLD-mediated transphosphatidylation, in the presence of 1-butanol. Cells were subcultured in six-well plates at $2 \times 10^{5} /$ well, and then incubated in the presence of $\left.3 \mu \mathrm{Ci} / \mathrm{ml}^{3}{ }^{3} \mathrm{H}\right]$ myristic acid. After overnight labeling, the cells were washed thrice with $5 \mathrm{ml}$ of PBS and preequilibrated in serum-free DMEM 
for $1 \mathrm{~h}$. PLD catalyzed transphosphatidylation in the presence of $0.5 \% 1$-butanol, and the extraction and characterization of lipids by thin layer chromatography were done as previously described (Ahn et al., 2003).

\section{Cell viability assay}

For the cell viability assay, an MTT assay was performed. Absorbance was measured using a spectrophotometer at $540 \mathrm{~nm}$, and viability was expressed relative to the control.

\section{Statistics}

The results are expressed as means \pm S.D. of the number of determinations indicated. Statistical significance of differences was determined by analysis of variance. A $P$ value less than 0.05 was considered to indicate statistical significance.

\section{Acknowledgements}

This work was supported by the Bio-Scientific Research Grant funded by the Pusan National University (PNU, Bio-Scientific Research Grant) (PNU-2008-101-103).

\section{References}

Ahn BH, Kim SY, Kim EH, Choi KS, Kwon TK, Lee YH, Chang JS, Kim MS, Jo YH, Min DS. Transmodulation between phospholipase $D$ and c-Src enhances cell proliferation. Mol Cell Biol 2003;23:3103-15

Buchanan FG, McReynolds M, Couvillon A, Kam Y, Holla VR, Dubois RN, Exton JH. Requirement of phospholipase D1 activity in H-RasV12-induced transformation. Proc Natl Acad Sci USA 2005;102:1638-42

Chang WT, Kang JJ, Lee KY, Wei K, Anderson E, Gotmare S, Ross JA, Rosen GD. Triptolide and chemotherapy cooperate in tumor cell apoptosis. A role for the p53 pathway. J Biol Chem 2001;276:2221-7

Chen BJ. Triptolide, a novel immunosuppressive and anti-inflammatory agent purified from a Chinese herb Tripterygium wilfordii Hook F. Leuk Lymphoma 2001;42: 253-65

Chen Y, Rodrik V, Foster DA. Alternative phospholipase $\mathrm{D} / \mathrm{mTOR}$ survival signal in human breast cancer cells. Oncogene 2005;24:672-9

Chen Y, Zheng Y, Foster DA. Phospholipase D confers rapamycin resistance in human breast cancer cells. Oncogene 2003;22:3937-42

Colley WC, Sung TC, Roll R, Jenco J, Hammond SM, Altshuller Y, Bar-Sagi D, Morris AJ, Frohman MA. Phospholipase D2, a distinct phospholipase D isoform with novel regulatory properties that provokes cytoskeletal reorganization. Current Biol 1997;7:191-201

Exton JH. Phospholipase D-structure, regulation and function. Rev Physiol Biochem Pharmacol 2002;144:1-94

Fidler JM, Li K, Chung C, Wei K, Ross JA, Gao M, Rosen GD.
PG490-88, a derivative of triptolide, causes tumor regression and sensitizes tumors to chemotherapy. Mol Cancer Ther 2003;2:855-62

Foster DA, Xu L. Phospholipase D in cell proliferation and cancer. Mol Cancer Res 2003;1:789-800

Frohman MA, Sung TC, Morris AJ. Mammalian phospholipase $D$ structure and regulation. Biochim Biophys Acta 1999;1439:175-86

Hammond SM, Altshuller YM, Sung TC, Rudge SA, Rose K, Engebrecht J, Morris AJ, Frohman MA. Human ADP-ribosylation factor-activated phosphatidylcholine-specific phospholipase $D$ defines a new and highly conserved gene family. J Biol Chem 1995;270:29640-3

Kang DW, Park MH, Lee YJ, Kim HS, Kwon TK, Park WS, Min DS. Phorbol ester up-regulates phospholipase D1 but not phospholipase D2 expression through a KC/Ras/ERK/ $\mathrm{NF} \kappa \mathrm{B}-$ dependent pathway and enhances matrix metalloproteinase- 9 secretion in colon cancer cells. J Biol Chem 2008;283:4094-104

Kim, YR, Byun HS, Won M, Park KA, Kim JM, Choi BL, Lee $\mathrm{H}$, Hong JH, Park J, Seok JH, Kim DW, Shong M, Park SK, Hur GM. Modulatory role of phospholipase D in the activation of signal transducer and activator of transcription (STAT)-3 by thyroid oncogenic kinase RET/PTC. BMC Cancer 2008; 8:144-54

Kiviharju TM, Lecane PS, Sellers RG, Peehl DM. Antiproliferative and proapoptotic activities of triptolide (PG490), a natural product entering clinical trials, on primary cultures of human prostatic epithelial cells. Clin Cancer Res 2002; 8:2666-74

Ko JK, Leung WC, Ho WK, Chiu P. Herbal diterpenoids induce growth arrest and apoptosis in colon cancer cells with increased expression of the nonsteroidal anti-inflammatory drug-activated gene. Eur J Pharmacol 2007;559:1-13

Lee KY, Chang W, Qiu D, Kao PN, Rosen GD. HPG490 (triptolide) cooperates with tumor necrosis factor-alpha to induce apoptosis in tumor cells. J Biol Chem 1999;274: 13451-5

Liu H, Liu ZH, Chen ZH, Yang JW, Li LS. Triptolide: a potent inhibitor of NF-KB in T-lymphocytes. Acta Pharm Sin 2000; 21:782-6

Min DS, Kwon TK, Park WS, Chang JS, Park SK, Ahn BH, Ryoo ZY, Lee YH, Lee YS, Rhie DJ, Yoon SH, Hahn SJ, Kim MS, Jo YH. Neoplastic transformation and tumorigenesis associated with overexpression of phospholipase $D$ isozymes in cultured murine fibroblasts. Carcinogenesis 2001; 22:1641-7

Miyata Y, Sato T, Ito A. Triptolide, a diterpenoid triepoxide, induces antitumor proliferation via activation of c-Jun $\mathrm{NH} 2$-terminal kinase 1 by decreasing phosphatidylinositol 3-kinase activity in human tumor cells. Biochem Biophys Res Commun. 2005;336:1081-6

Noh DY, Ahn SJ, Lee RA, Park IA, Kim JH, Suh PG, Ryu SH, Lee $\mathrm{KH}$, Han JS. Overexpression of phospholipase D in human breast cancer tissues. Cancer Lett 2000;161:207-14 Park MH, Ahn BH, Hong YK, Min DS. Overexpression of 
phospholipase $\mathrm{D}$ enhances matrix metalloproteinase-2 expression and glioma cell invasion via protein kinase $C$ and protein kinase A/NF-kappaB/Sp1-mediated signaling pathways. Carcinogenesis 2009;30:356-65

Qiu D, Kao PN. Immunosuppressive and anti-inflammatory mechanisms of triptolide, the principal active diterpenoid from the Chinese medicinal herb Tripterygium wilfordii Hook. f. Drugs R D 2003;4:1-18

Qiu D, Zhao G, Aoki Y, Shi L, Uyei A, Nazarian S, Ng JC, Kao PN. Immunosuppressant PG490 (triptolide) inhibits T-cell interleukin-2 expression at the level of purine-box/nuclear factor of activated T-cells and NF-kappaB transcriptional activation. J Biol Chem 1999;274:13443-50

Saito M, Iwadate M, Higashimoto M, Ono K, Takebayashi Y, Takenoshita S. Expression of phospholipase D2 in human colorectal carcinoma. Oncol Rep 2007;18:1329-34

Scott SA, Selvy PE, Buck JR, Cho HP, Criswell TL, Thomas $\mathrm{AL}$, Armstrong MD, Arteaga CL, Lindsley CW, Brown HA. Design of isoform-selective phospholipase $D$ inhibitors that modulate cancer cell invasiveness. Nat Chem Biol 2009; 5:1008-17

Shamon LA, Pezzuto JM, Graves JM, Mehta RR, Wangcharoentrakul S, Sangsuwan R, Chaichana S, Tuchinda P, Cleason P, Reutrakul V. Evaluation of the mutagenic, cytotoxic, and antitumor potential of triptolide, a highly oxygenated diterpene isolated from Tripterygium wilfordii. Cancer Lett 1997;112:113-7
Tengchaisri T, Chawengkirttikul R, Rachaphaew N, Reutrakul V, Sangsuwan R, Sirisinha S. Antitumor activity of triptolide against cholangiocarcinoma growth in vitro and in hamsters. Cancer Lett 1998;133:169-75

Uchida, N, Okamura S, Kuwano H. Phospholipase D activity in human gastric carcinoma. Anti-Cancer Res 1999;19: 671-5

Williger BT, Ho WT, Exton JH. Phospholipase D mediates matrix metalloproteinase-9 secretion in phorbol ester-stimulated human fibrosarcoma cells. J Biol Chem 1999;274: 735-8

Xiang $\mathrm{M}$, Zhang $\mathrm{C}$. Advances in studies on immunosuppression of Tripterygium wilfordii. Chinese Traditional and Herbal Drugs 2005;36:458-61

Yang S, Chen J, Guo Z, Xu XM, Wang L, Pei XF, Yang J, Underhill CB, Zhang L. Triptolide inhibits the growth and metastasis of solid tumors. Mol Cancer Ther 2003;2:65-72

YinJun L, Jie W, YunGui W. Triptolide inhibits transcriptional factor $N F \kappa B$ and induces apoptosis of multiple myeloma cells. Leukemia Res 2005;29:99-105

Zhao Y, Ehara H, Akao Y, Shamoto M, Nakagawa Y, Banno Y, Deguchi T, Ohishi N, Yagi K, Nozawa Y. Increased activity and intranuclear expression of phospholipase D2 in human renal cancer. Biochem Biophys Res Commun 2000;278: $140-3$ 